\title{
Prophylactic Effect of Dietary Supplementation of Fish Oil Extracted from Sardinella Longiceps on Renal Dysfunction in Alloxan Induced Diabetic Mice (Mus Musculus)
}

\author{
Shantal Ganapati Kamat, Celina J Mascarenhas and Ramaballav Roy*
}

Department of Zoology, Goa University, Taleigao Plateau 403206, Goa, India

*Corresponding author: Ramaballav Roy, Department of Zoology, Goa University, Taleigao Plateau 403206, Goa, India, Tel: +91-9421241643; E-mail: rroy@unigoa.ac.in

\begin{abstract}
Diabetes mellitus is a multifactorial metabolic disorder caused due to deficiency of pancreatic hormone insulin, which results in failure to metabolize sugar or due to adequacy of another pancreatic hormone glucagon which results in the increased liver glucose output. Oxidative stress plays exquisite role in diabetes, which results in pathogenesis of diabetes related long term vascular complications which are the main cause of morbidity and mortality in diabetic patients. These vascular complications also result in Diabetic kidney disease (DKD) which is the single most common cause of end stage renal disease (ESRD). The present study was being aimed to evaluate the effect of fish oil on diabetic kidney damage. Diabetes was induced by repetitive intra-peritoneal injection of alloxan $(100 \mathrm{mg} / \mathrm{kg} \mathrm{BW})$. The diabetic mice were fed the commercial pellet diet supplemented with $10 \%$ laboratory extracted fish oil of Sardinella longiceps for a period of one month. Concentration of various parameters like creatinine, uric acid, urea, protein, albumin and globulin in serum and kidney were estimated. The antioxidant parameters like vitamin C, vitamin E, GSH, SOD and Catalase, lipid peroxidation parameters like TBARS and GGT were also monitored, along with the activity of ALP and ACP. The Altered level of tissue biochemical composition and antioxidant status due to diabetes induced damages was nearly brought down to normal levels with the supplementation of 10\% Sardinella fish oil.
\end{abstract}

Received date: April 04, 2016

Accepted date: May 09, 2016

Published date: May 13, 2016

Citation: Roy, R., et al. Prophylactic Effect of Dietary Supplementation of Fish Oil Extracted from Sardinella Longiceps on Renal Dysfunction in Alloxan Induced Diabetic Mice (Mus Musculus). (2016) J Diabetes Obes 3(1): 8- 15.

DOI: $10.15436 / 2376-0494.16 .853$

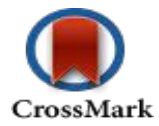

Keywords: Diabetes; Sardinella; Fish oil; Kidney diseases; PUFA; Oxidative stress

\begin{abstract}
Abbreviations: PUFA: Polyunsaturated Fatty Acid; ALT: Alanine Transaminase; AST: Aspartate Transaminase; ALP: Alkaline Phosphates; LDH: lactate dehydrogenase; ACP: Acid Phosphatase; GGT: gamma glutamyl transpeptidase; TBARS: Thiobarbitaric Acid Reactive Substance; GSH: Reduced Glutathione; SOD: Superoxide Dismutase; EPA: Eicosapentaenoic Acid; DHA: Docosahexaenoic Acid; TGF $\beta$ : Transforming Growth Factor $\beta$; AGE: Advanced Glycation End Products; PKC: Activation of Protein Kinase C
\end{abstract}

\section{Introduction}

Diabetes mellitus is a chronic metabolic disorder characterized by the presence of hyperglycemia due to the defective insulin mechanism. Diabetes mellitus is the main cause of end-stage renal failure around the world in both developed and underdeveloped countries ${ }^{[1]}$ The complex metabolic, vascular and inflammatory disconcertion that characterize diabetes mellitus frequently lead to progressive albuminuria, renal injury and dysfunction ${ }^{[2]}$ through complex overlapping pathways like: formation of advanced glycation end products (AGE), activation of protein kinase C (PKC), and generation of reactive oxygen species (ROS) in hyperglycemia induces vascular injuries. Growing evidence suggests that these complications are associated with modification in pathophysiology of lipids and that this damage appears to be largely because of ROS which plays a vital part in the commencement and 
progression of diabetic nephropathy ${ }^{[3]}$. Although there are treatments to delay the relentless progression of end-stage renal disease that occurs in diabetic patients who are susceptible to nephropathy, these agents do not prevent this disorder. Hence, the improved therapy is required to further optimize the renal protection in diabetes ${ }^{[4]}$.

Dietary lipid helps to keeps up well-being and plays an essential role in physiological developments ${ }^{[5]}$. The long chain omega-3 and omega-6 PUFAs produce distinct types of prostaglandins and thromboxanes through lipoxygenase and cyclooxygenase pathways, each of which has very different effects in the body and act in antagonistic manner. These eicosanoids act as potent regulator of vital body functions and play role in immune system and inflammatory responses ${ }^{[6]}$. Large number of studies showed that PUFA plays a significant role in new born development and growth ${ }^{[7]}$. It also helps for intellectual growth of the brain ${ }^{[8]}$. PUFA, mainly eicosapentaenoic acid (EPA; 20:5n-3) and docosahexaenoic acid (DHA; 22:6n-3) existing in marine sources, have been found to have therapeutic effects against numerous oxidative stress related complication ${ }^{[9]}$. The fatty acid composition of these fish oils was previously reported ${ }^{[10]}$. In brief, Sardinella fish oil is rich in unsaturated fatty acids (54\%) including n-3 fatty acids (38\%) and n-6 fatty acids (14\%); it also contains 12\% EPA and 20\% DHA. Hence the present work was designed to test the potential properties of fish oil extracted from Sardinella longiceps to protect the kidney from alloxan induced Diabetic renal damage. We induced diabetes in Swiss albino mice, Mus musculus with repetitive intra- peritoneal injection of alloxan, which is capable of inducing diabetes type 1 . We supplemented these diabetes induced mice with $10 \%$ laboratory extracted Sardinella longiceps fish oil rich with omega 3 PUFAs.

\section{Material and Methods: Protocol}

Prior permission of Animal Ethics Committee, Goa University was taken to use the Swiss albino mice for the study. Male Swiss albino mice weighing $25 \pm 0.5 \mathrm{~g}$ were used for the present work and they were maintained as per guidelines of CPCSEA (Committee for the Purpose of Control and Supervision on Experiments on Animals, Government of India). The animals were fed with a pellet diet containing nearly $3-4 \%$ of lipid ad libitum. The animals were divided into 3 groups. Group one (control; PC) were

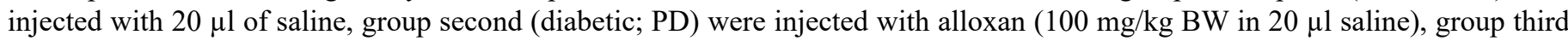
were injected with same dose of alloxan ${ }^{[11]}$ (Chougule et al., 2007) and supplemented with $10 \%$ Sardinella longiceps fish oil freshly blended with pellet feed. The diabetic conditions in PD and SD groups were maintained by repetitive dosage of alloxan after every 5 th day ${ }^{[12]}$. After completion of one month, the animals were sacrificed by cervical dislocation to collect blood and kidney tissues.

\section{Biochemical and enzymatic assays}

The concentration of urea, using diacetyl monoxime reagent ${ }^{[13]}$, protein, using Lowry's reagent ${ }^{[14]}$ uric acid, using phosphotungstic acid reagent ${ }^{[15]}$, creatinine, using alkaline picric acid reagent ${ }^{[15]}$, albumin and globulin, using albumin reagent ${ }^{[15]}$ were measured, along with the activities of alkaline phosphatase (ALP), by using p-nitrophenol reagent ${ }^{[16]}$, acid phosphatase (ACP), by using p- nitrophenyl phosphate reagent ${ }^{[17]}$ were measured in serum as well as in kidney tissues.

For analyzing antioxidant and lipid peroxidation status vitamin $\mathrm{C}$, using dinitrophenylhydrazine ${ }^{[18]}$, vitamin $\mathrm{E}$, using ferric chloride reagent ${ }^{[19]}$, Thiobarbituric Acid Reactive Species (TBARS), using TBA-TCA-HCL reagent ${ }^{[20]}$, reduced glutathione (GSH), using 5,5-dithiobis, 2-nitrobenzoic acid ${ }^{[21]}$, activity of superoxide dismutase (SOD) by using SOD substrate reagent ${ }^{[22]}$, activity of catalase by using dichromate acetic acid reagent ${ }^{[23]}$ and activity of gamma Glutamyl Trans Peptidase (GGT), by using glacial acetic acid reagent ${ }^{[24]}$ were measured in serum and kidney tissues.

\section{Histological study}

Routine laboratory method was followed for histological studies ${ }^{[25]}$. Kidney tissue were perfused with phosphate buffer saline ( $\mathrm{pH}$ 7.0) and fixed in $10 \%$ formalin. The paraffin block was cut into uniform sections of $10 \mu \mathrm{m}$ thickness using a microtome and tissue sections were stained with hematoxylin and eosin for histological examination under a polarizing microscope (Olympus BX41).

Expression of TGF $\beta$ (transforming growth factor $\beta$ ): The total RNA was extracted from the kidney tissue using TRIzol reagent (Ambion, life technologies) ${ }^{[26]}$. cDNA was synthesized using HiScript One Step reverse transcriptase-PCR cDNA synthesis kit (HIMEDIA). The reaction mixture was prepared in the PCR tube according to the kit procedure. It was mixed gently to make sure that all the components were at the bottom of the amplification tube and placed in thermal cycler as per the program mentioned in kit for cDNA synthesis. $\beta$-actin gene was used as housekeeping gene to study the mRNA expression.

The primers used for present study are given: $\beta$-actin: LP5'TCTAGGCACCAAGGTGTG3' RP5'TCATGAGGTAGTCCGTCAGG3'; TGFß: LP 5'TCGCTTTGTACAACAGCACC3' RP 5' GCACTGCTTCCCGAATGTC3'.

\section{Statistical analysis}

Statistical analyses were performed using the Statistical Package for the Social Sciences, Version 21 (IBM SPSS Statistic) for comparison between the control, diabetes and diabetes plus fish oil administered groups. The difference between the groups were analysed by using student $t$ test. The results were represented as mean \pm standard error. 


\section{Result}

The alloxan induced diabetes caused kidney damage like complete distortion of normal structure due glomerular enlargement and certain degree of inflammation when compared to the control mice kidney which showed normal renal tubules and glomerulus. Dietary intake of Sardinella fish oil helped to restore the normal structure of the kidney (Figure 1).
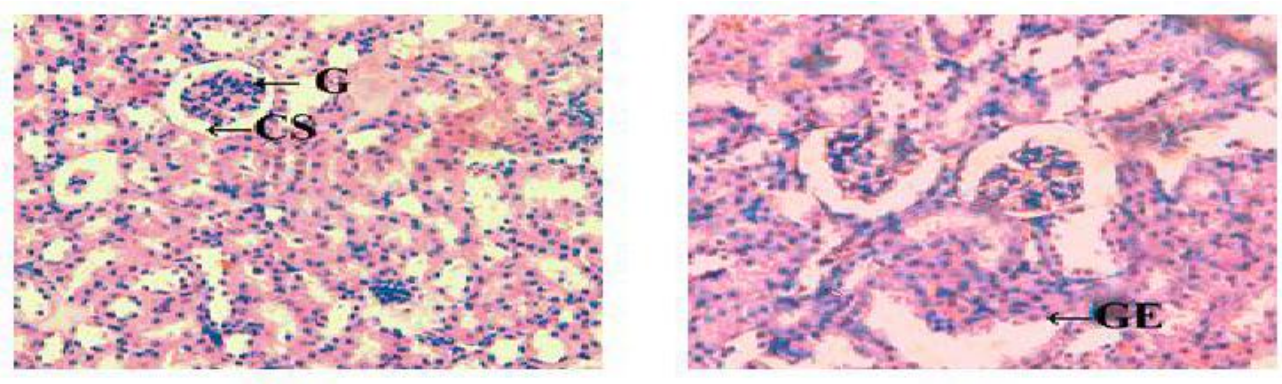

(A)

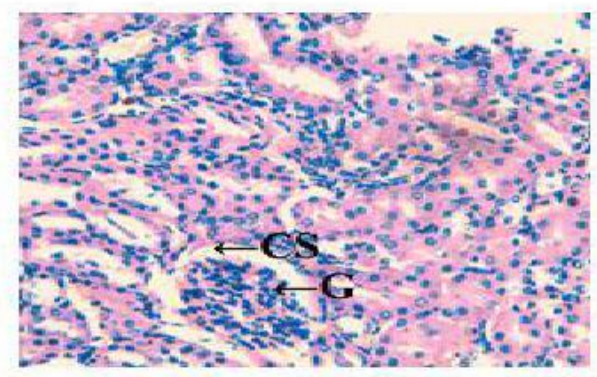

(c)

Figure 1: Histological changes in kidney tissues of mice (A) control group showing normal kidney architechure (B) mice of diabetic group showing destortion of kidney due to inflammation (C) mice of SD group showing less damage (G-Glomerulus, GE- Glomerular expansion, CSCapsular space, I- Inflammation).

The induction of diabetes significantly $(\mathrm{P}<0.01-0.0001)$ brought down the level vitamin $\mathrm{C}$, vitamin $\mathrm{E}$ and reduced glutathione (GSH) by $25-65 \%$ and augmented $(\mathrm{P}<0.0001)$ levels of thiobarbituric acid reactive species (TBARS) by $1.5-5.5$ fold (Table 1) with decrease $(\mathrm{P}<0.01-0.0001)$ in the activities of superoxide dismutase (SOD), catalase (CAT) by $15-40 \%$ with 25 - 55\% increase $(\mathrm{P}<0.0001)$ in gamma glutamyl transpeptidase (GGT) activity in serum and kidney tissues (Table 2). The dietary supplementation of fish oil raised $(\mathrm{P}<0.05)$ the level of antioxidants vitamin $\mathrm{C}$, vitamin $\mathrm{E}$, GSH along with the activities of SOD, catalase by $20 \%-1.9$ fold and also decreased $(\mathrm{P}<0.001-0.0001)$ in levels of TBARS and in the activity of GGT by $20-70 \%(\mathrm{P}$ $<0.001-0.0001)$. The changes due to induction of diabetes were also reflected in activities of functional enzymes. The prolonged diabetes significantly $(\mathrm{P}<0.0001)$ elevated the activities of alkaline phosphatase (ALP) and acid phosphatase (ACP) by $60 \%-1.9$ fold serum and kidney tissues (Figure 2). Following supplementation with Sardinella fish oil these elevated levels of enzymatic activity decreased $(\mathrm{P}<0.001)$ by $20-35 \%$.

Table 1: Effect of dietary supplementation of fish oil on the concentration of various antioxidants and lipid peroxidation parameters in serum (concentration/dL) and kidney (concentration/100 mg) tissues of alloxan induced diabetic mice (Mus musculus). Data represented as mean of six values and their standard errors.

\begin{tabular}{|c|c|c|c|c|c|c|}
\hline \multirow[t]{2}{*}{ Parameters } & \multicolumn{3}{|c|}{ Serum } & \multicolumn{3}{|c|}{ Kidney } \\
\hline & PC & PD & SD & PC & PD & SD \\
\hline $\begin{array}{l}\text { Vitamin C } \\
(\mathrm{mg})\end{array}$ & $144.7 \pm 2.11$ & $66.2 * \pm 2$ & $123.2 * \dagger \pm 1.82$ & $1.47 \pm 0.20$ & $0.653^{*} \pm 0.075$ & $1.402 * \dagger \pm 0.20$ \\
\hline $\begin{array}{l}\text { Vitamin E } \\
\text { (nmole) }\end{array}$ & $6300.3 \pm 12.2$ & $3330.3 * \pm 10.8$ & $5217.8 * \dagger \pm 6.74$ & $59.68 \pm 0.99$ & $44.46^{*} \pm 0.75$ & $52.95 * \dagger \pm 0.72$ \\
\hline $\begin{array}{l}\text { Reduced Glutathi- } \\
\text { one } \\
\text { (umole) }\end{array}$ & $2247.6 \pm 80.4$ & $1310.5^{*} \pm 112$ & $1950.3 * \dagger \pm 50.6$ & $0.496 \pm 0.022$ & $0.207^{*} \pm 0.013$ & $0.275 * \dagger \pm 0.032$ \\
\hline $\begin{array}{l}\text { TBARS } \\
\text { (umole) }\end{array}$ & $0.262 \pm 0.0036$ & $1.75^{*} \pm 0.0052$ & $0.505 * \dagger \pm 0.0018$ & $0.222 \pm 0.010$ & $0.526^{*} \pm 0.026$ & $0.362 * \dagger \pm 0.018$ \\
\hline
\end{tabular}

The significant difference between groups for each tissues based on student $\mathrm{t}$ test represented by * compared to PC, $\dagger$ compared to PD, 
Renal Dysfunction in Alloxan Induced Diabetic Mice

Table 2: Effect of dietary supplementation of fish oil on the concentration of various antioxidant and lipid peroxidation enzymes in serum and kidney tissues of alloxan induced diabetic mice (Mus musculus). Data represented as mean of six values and their standard errors.

\begin{tabular}{|l|c|c|c|c|c|c|}
\hline \multirow{2}{*}{ Parameters } & \multicolumn{3}{|c|}{ Serum } & \multicolumn{3}{c|}{ Kidney } \\
\cline { 2 - 7 } & PC & PD & SD & PC & PD & SD \\
\hline $\begin{array}{l}\text { SOD } \\
\text { (IU/mg protein) }\end{array}$ & $12.03 \pm 0.33$ & $8.39^{*} \pm 0.26$ & $10.2 * \dagger \pm 0.27$ & $11.9 \pm 0.31$ & $6.7 * \pm 0.29$ & $9.7 * \dagger \pm 0.30$ \\
\hline $\begin{array}{l}\text { Catalase } \\
\left(\begin{array}{l}\mathbf{H}_{2} \mathbf{O}_{2} / \mathbf{m i n} / \mathbf{m g} \\
\text { protein) }\end{array}\right.\end{array}$ & $168.7 \pm 1.15$ & $135.9 * \pm 1.42$ & $220 * \dagger \pm 1.06$ & $200 \pm 1.3$ & $139.9 * \pm 1.07$ & $178.7 * \dagger \pm 1.32$ \\
\hline $\begin{array}{l}\text { GGT } \\
\text { (IU/mg protein) }\end{array}$ & $12.7 \pm 0.71$ & $16.1 * \pm 0.88$ & $12.76 \dagger \pm 0.79$ & $10.1 \pm 0.36$ & $16.1 * \pm 0.49$ & $12.7 * \dagger \pm 0.49$ \\
\hline
\end{tabular}

The significant difference between groups for each tissues based on student $t$ test represented by * compared to PC, $\dagger$ compared to PD,

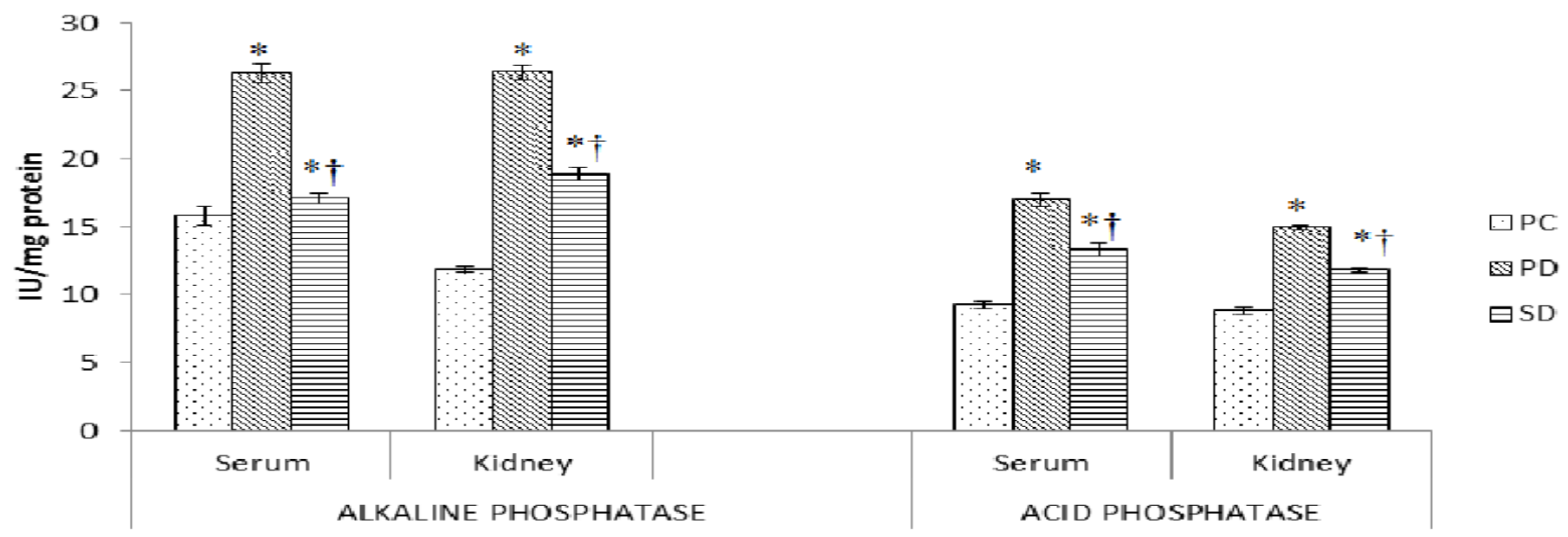

Figure 2: Effect of dietary supplementation of fish oils on activity of enzymes in alloxan induced diabetic mice (Mus musculus). Data represented as mean of six values and their standard errors. The significant difference between groups for each tissues based on student $t$ test represented by * compared to $\mathrm{PC}, \dagger$ compared to $\mathrm{PD}$

Induction of diabetes resulted in $60-90 \%$ decrease $(\mathrm{P}<0.0001)$ in total protein, albumin and globulin concentration in serum and kidney tissues. The supplementation of fish oil raised the decreased level of protein, albumin and globulin concentration by $30-70 \%$ in these tissues (Table 3 ). The induction of diabetes also resulted in $90 \%-4$ fold increase $(\mathrm{P}<0.0001)$ in serum and kidney tissues concentration of urea, uric acid and creatinine. The supplementation of fish oil helped to decrease the elevated level of urea, uric acid and creatinine by $25-55 \%$ in these tissues (Figure $3 \mathrm{~A}$ and 3B).

Table 3: Effect of dietary supplementation of fish oil on the concentration of protein, albumin and globulin concentration in serum (mg/dl) and kidney ( $\mathrm{mg} / 100 \mathrm{mg}$ tissue) tissues of alloxan induced diabetic mice (Mus musculus). Data represented as mean of six values and their standard errors.

\begin{tabular}{|l|l|c|c|c|c|c|}
\hline \multirow{2}{*}{ Parameters } & \multicolumn{3}{|c}{ Serum } & \multicolumn{2}{c|}{ Kidney } \\
\cline { 2 - 7 } & \multicolumn{1}{|c|}{ PC } & PD & SD & PC & PD & SD \\
\hline Protein & $2.94 \pm 0.78$ & $1.43^{*} \pm 0.58$ & $2.38^{* \dagger} \pm 0.47$ & $6.58 \pm 0.34$ & $1.27^{*} \pm 0.10$ & $2.20^{*} \dagger \pm 0.21$ \\
\hline Albumin & $1.2 \pm 0.37$ & $0.678^{*} \pm 0.096$ & $0.992^{* \dagger} \pm 0.27$ & $3.14 \pm 0.13$ & $0.960^{*} \pm 0.10$ & $1.65^{*} \dagger \pm 0.11$ \\
\hline Globulin & $1.69 \pm 0.45$ & $0.748^{*} \pm 0.39$ & $1.384^{* \dagger} \pm 0.32$ & $3.44 \pm 0.10$ & $0.316^{*} \pm 0.057$ & $0.569^{*} \dagger \pm 0.087$ \\
\hline
\end{tabular}

The significant difference between groups for each tissues based on student $t$ test represented by * compared to PC, $\dagger$ compared to PD, 


\section{Serum}

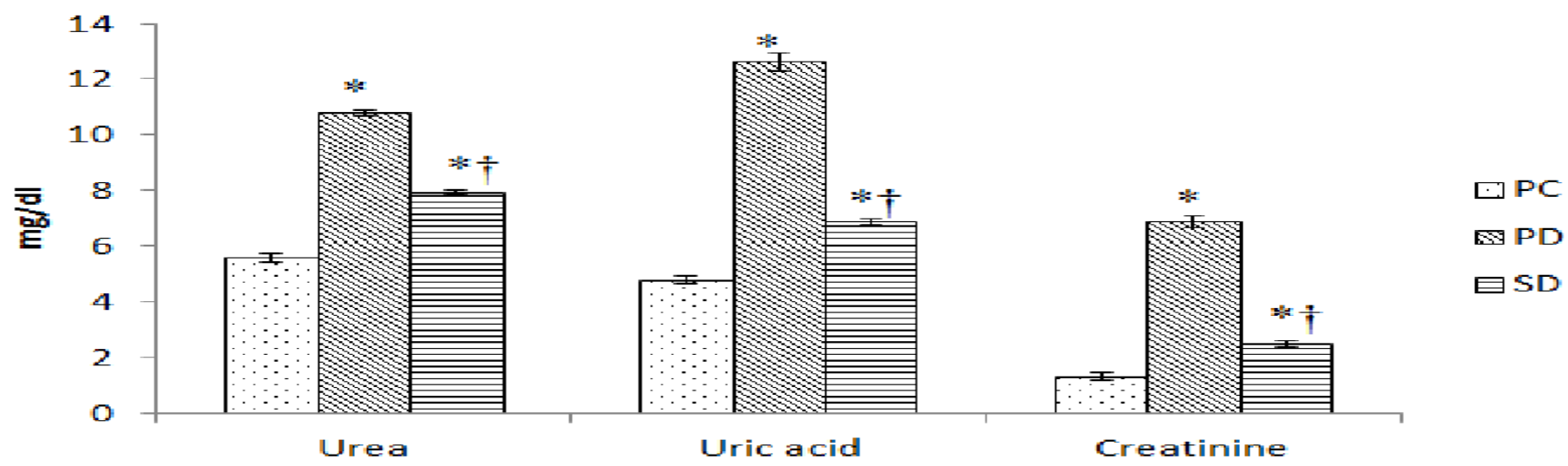

Figure 3A: Effect of dietary supplementation of fish oils on concentration of urea, uric acid and creatinine in serum of alloxan induced diabetic mice (Mus musculus). Data represented as mean of six values and their standard errors. The significant difference between groups for each tissues based on student $t$ test represented by * compared to PC, $\uparrow$ compared to PD

\section{Kidney}

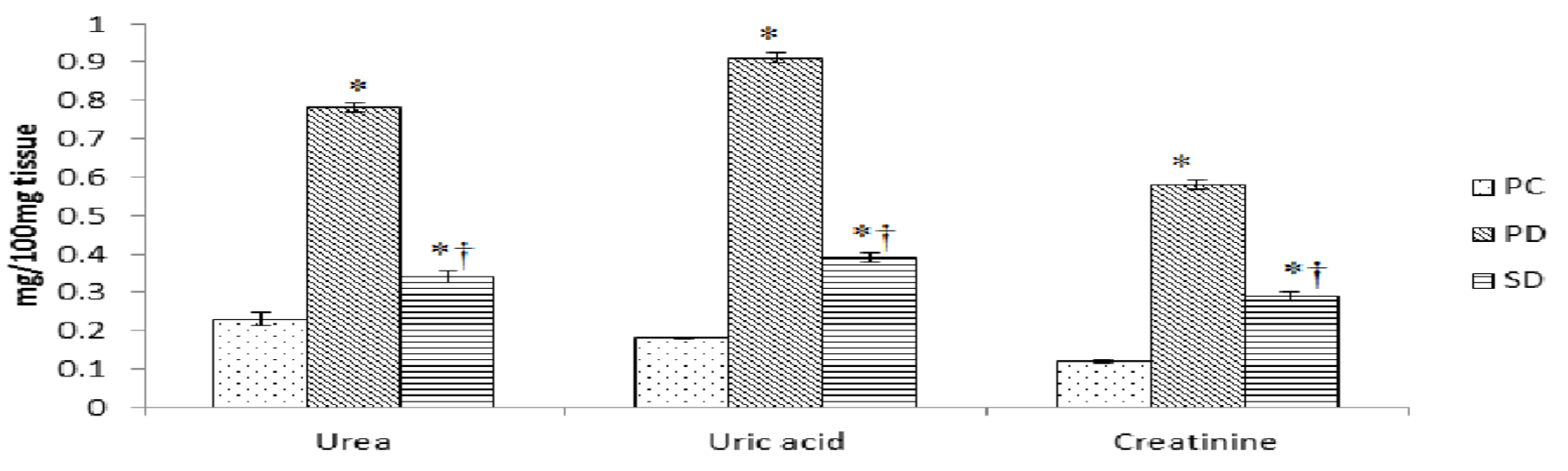

Figure 3B: Effect of dietary supplementation of fish oils on concentration of urea, uric acid and creatinine in kidney of alloxan induced diabetic mice (Mus musculus). Data represented as mean of six values and their standard errors. The significant difference between groups for each tissues based on student $\mathrm{t}$ test represented by * compared to $\mathrm{PC}, \uparrow$ compared to PD

TGF $\beta$ is multifunctional cytokine which acts as key mediator of glomerular and tubulointerstitial pathobiology in chronic kidney diseases. Induction of diabetes resulted in nearly 95\% increase $(\mathrm{P}<0.0001)$ in expression of TGF $\beta$ in kidney tissue. The supplementation of Sardinella fish oil to the diabetic group of mice significantly $(\mathrm{P}<0.0001)$ brought down the elevated level by $45 \%$ (Figure 4$)$.

\section{TGFB}

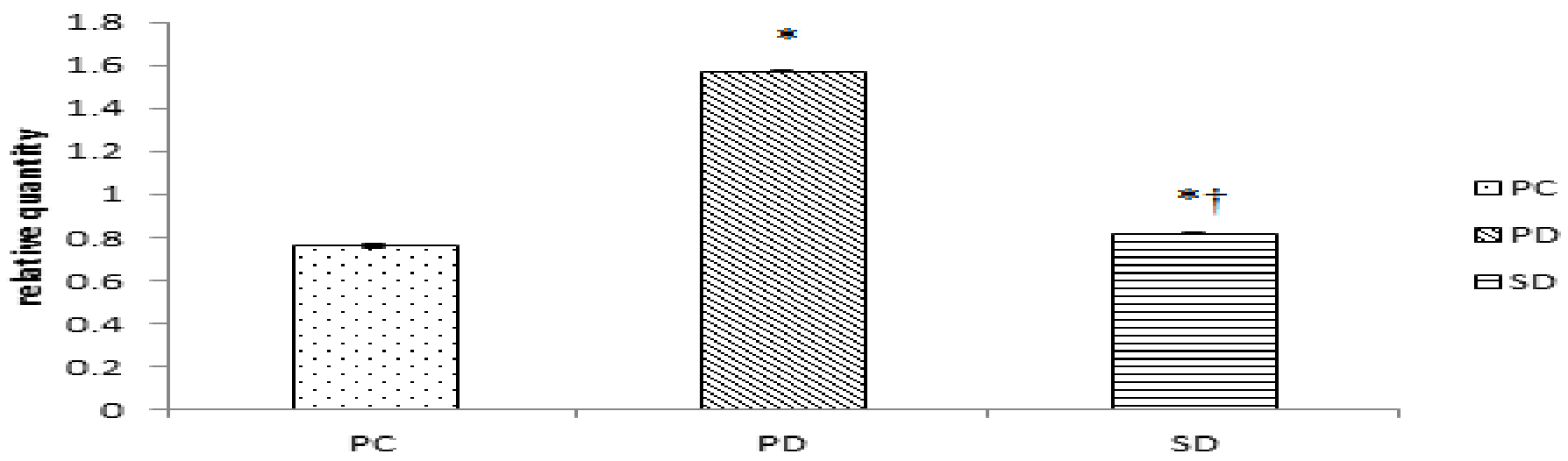

Figure 4: Effect of dietary supplementation of fish oils on relative quantity of expression of TGF $\beta$ in alloxan induced diabetic mice (Mus musculus). Data represented as mean of six values and their standard errors. The significant difference between groups for each tissues based on student $t$ test represented by * compared to PC, $\uparrow$ compared to PD 


\section{Discussion}

Diabetes mellitus impairs the ability of a cell or tissue to cope with the increased oxidative burden by stimulating the generation of ROS, which leads to vascular complications ${ }^{[27]}$. Over the past $10-15$ years research has validated the health benefits associated with consumption of fish oil rich with omega-3 polyunsaturated fatty acids. These omega-3 PUFAs have proven to attenuate oxidative stress $^{[28]}$ and they are having anti-inflammatory effects ${ }^{[29]}$. The present work focuses on the beneficial effect of Sardinella longiceps fish oil to reverse the prolonged diabetic metabolic changes and the kidney tissue damages. Administration of alloxan to experimental animals structurally deformed kidney. Diabetic mice showed kidney with distortion, glomerular enlargement and inflammation. This could be ascribed to subsequent effects of hyperglycemia, which induces degenerative changes in the kidney, which may be due to the increased ROS generation ${ }^{[30]}$. The diabetes also resulted in significant decrease protein concentration. The decrease may be due to faulty glucose utilization causing hyperglycemia ${ }^{[31]}$. Diabetes mice also showed the decrease in levels of albumin and globulin concentration. These changes may be attributed to glomerular dysfunction and increased abundance of growth factors $^{[32]}$. We have also observed that serum and kidney uric acid and urea concentration were increased in diabetic mice when compared to control. This may be due to increased levels of sugar which results in increased nucleotide turnover and nucleotide synthesis resulting in elevated levels of uric acids and urea ${ }^{[33]}$. Serotonin levels in the diabetic mice were also increased which may be due to damage caused to the functioning nephrons ${ }^{[34]}$.

Diabetes also resulted in alterations in the lipid peroxidation and antioxidant status. SOD and catalase, which are free radical scavenging enzymes and GSH, which counterbalance free radical facilitated damage and acts as endogenous antioxidant ${ }^{[35]}$ along with vitamin $\mathrm{E}$, vitamin $\mathrm{C}$, antioxidants are decreased with a rise in TBARS and GGT concentration in all tissues of diabetic mice. The reason for this change is might be excessive lipid peroxidation and the generation of free radicals. Oxidative stress triggered by extreme production of superoxide and an inequity in antioxidant enzymes or increased consumption might be the reason for a reduction in the level of biomolecules and enzymatic antioxidant status in tissues of diabetic mice ${ }^{[36]}$. Diabetes significantly increased the activities of ALP and ACP when compared to non-diabetic control which is directly related to changes in metabolism where in these enzymes are involved ${ }^{[37]}$. Elevation in ALP activity might be due to the disturbance in the transport of metabolites ${ }^{[38]}$ and an increase in ACP activity might be due to necrosis of liver ${ }^{[39]}$.

Diabetes also resulted in an increase in cytokine expression of TGF $\beta$ in kidney supporting a role for inflammation in diabetes. TGF $\beta$ is a multifunctional cytokine which acts as a key mediator of glomerular and tubulointerstitial Pathobiology in chronic kidney diseases ${ }^{[40]}$.

Supplementation of fish oil to the diabetic mice group helped to restore the kidney tissue architecture which is also reflected in biochemical composition. Previously we have also reported the effect of different fish oil in restoring the normal function of tissues like liver, kidney, heart and pancreas ${ }^{[10]}$. It resulted in an increase in concentration of protein, albumin and globulin. This might be due to the fact that proteins were spared from energy yielding processes as the diets were enriched with PUFA. The PUFA composition of a diet influences the utilization of fat for energy yielding processes ${ }^{[41]}$. The supplementation of fish oil also helps to recover the normal concentration of serotonin, urea and uric acid in serum and urine. This is also supported from prior studies that reported Omega-3 fatty acids improve renal functioning in patients who undergo heart and kidney transplants ${ }^{[42]}$. Urakaze

et $a l^{[43]}$ reviewed several studies done on the effect of omega-3 fatty acids on human subjects with renal disease by assessing serum creatinine among other factors and concludes that two studies reported a statistically significant improvement in serum creatinine when treated with PUFA. In the present study, the antioxidant status of fish oil supplemented diabetic mice also improved. The concentration of antioxidants like GSH, vitamin E and vitamin C and activity of antioxidant enzymes SOD, catalase is elevated to decrease in lipid peroxidation variables like TBARS and GGT due to the supplementation of Sardinella fish oil. This indicates that omega-3 PUFAs rich fish oil is having a useful effect on attenuation of oxidative stress and antioxidant prospective which is in support with earlier results ${ }^{[44]}$. The significant decrease in enzyme activity of ALP and ACP was provoked by supplementation of fish oil, which is held by previous findings, which showed that in experimental animals oral feeding of oils rich in $\omega-3$ EPA and DHA helps to prohibit the development of induced diabetes mellitus ${ }^{[45]}$. The expression of TGF $\beta$ in the Sardinella fish oil supplemented group lowered in spite of alloxan induced diabetes. It is specified by the studies that omega-3 PUFA and their explicit lipid mediators can diminish the process of activation of inflammation ${ }^{[45]}$.

In conclusion, the present study firmly and significantly throws light on the valuable contribution of supplementation with fish oils rich with PUFA on antioxidant property, beneficial effect on attenuation of oxidative stress. The long term supplementation of fish oils enriched with omega-3 PUFAs is having the anti-inflammatory potential to arrest cellular damage and may be useful in the management of oxidative stress induced kidney tissue damage caused by prolonged diabetes.

Acknowledgement: Financial support from the University Grant Commission- Special Assistance Programme India (Sanction letter no. F.3-3/2011 (SAPII) is acknowledged.

Disclosure Statement: The study was carried out in strict accordance as per the guidelines of CPCSEA (Committee for the Purpose of Control and Supervision on Experiments on Animals, Govt. of India). The authors declare that they have no conflicts of interest concerning this article. 


\section{References}

1. Nasri, H., On the occasion of the world diabetes day 2013; diabetes education and prevention; a nephrology point of view. (2013) J Renal Inj Prev 2(2): 31-32.

2. Shapiro, H., Theilla, M., Attal-Singer, J., et al. Effects of polyunsaturated fatty acid consumption in diabetic nephropathy. (2011) Nature Reviews Nephrology 7(2): 110-121.

3. Lee, B.H., Ha, H., King, G.L. Reactive oxygen species and diabetic neohropathy. (2003) JASN 14(3): S209-S210.

4. Tolouian, R., Hernandez, T. Prediction of Diabetic Nephropathy: The need for a sweet biomarker. (2013) J Nephropathol 2(1): 4-5.

5. Glick, D. Methods of biochemical analysis. (2009) Interscience publishers, Inc. New York Ricciotti, E., FiltzGerald, G.A. Prostaglandins and inflammation. (2012) Arterioscler Thromb Vasc Biol 31(5): 986-100.

6. Lauritzen, L., Jørgensen, M., Olsen, S., et al. Maternal fish oil supplementation in lactation: Effect on visual acuity and n-3 fatty acid content of infant erythrocytes. (2004) Lipids 39(3): 195-206.

7. Matorras, R., Perteagudo, L., Ruiz, JI., et al. Intake of long chain w3 polyunsaturated fatty acids during pregnancy and the influence of levels in the mother on newborn levels. (1999) Euro J Obstetrics Gynec Reprod Biol 83(2):179-184.

8. Siriwardhana, N., Kalupahana, N.S., Moustaid-Moussa, N. Health benefits of n-3 polyunsaturated fatty acids: eicosapentaenoic acid and docosahexaenoic acid. (2012) Adv Food Nutr Res 65:211-222.

9. Niedowicz, D.M., Daleke, D.L. The role of oxidative stress in diabetic complications, (2005) Cell biochem biophys 43(2): 289-330.

10. Chougule, A.D., Panaskar, S.N., Gurao, P.M., et al. Optimization of alloxan dose is essential to induce stable diabetes for prolonged period. (2007) Asian j Biochem 2(6): 402-408.

11. Uslu, B.A., Ilhan, F., Gulyuzf, F., et al. Assessment of histopathological changes occurring in the testis of the mice suffering from experimental diabetes induced using alloxan. (2009) J Anim Vet Adv 8(10): 1929-1935.

12. Friedman, H.S. Modification of the determination of urea by the diacetyl monoxime method. (1953) J Analytical Chemistry 25(4): 662-664.

13. Lowry, O.H., Rosenbrough, N.J., Randal, R.J. Protein measurement with folin phenol reagent. (1951) J Biol Chem 193(1):265-275.

14. Godkar, P.B. Clinical biochemistry principle and practice. (1994) Bhalani publishing house, India.

15. King, E.J., Armstrong, A.R. A convenient method for determining serum and bile phosphatase activity. (1934) Can Med Assoc J 31(4): 376381.

16. Andersch, M.A., Szczypinski, A.J. Use of P-nitrophenylphosphate as the substrate in determination of serum acid phosphatase. (1947) Am J Clin Path 17(7): 571-604.

17. Roe, J.H., Kuether, C.A. The determination of ascorbic acid in whole blood and urine through 2, 4-Dinitrophenyl hydrazine derivative of dehydroascorbic acid. (1943) Biochem J 147:399- 407.

18. Baker, H., Frank, O., De Angelis, B., et al. Plasma tocopherol in man at various times after ingesting free or acetylated tocopherol. (1980) Nutr Res Int 21: 531-536.

19. Niehaus, W.G., Samuelsson, B. Formation of malondialdehyde from phospholipid arachidonate during microsomal lipid peroxidation. (1968) Eur J Biochem 6(1): 126-130.

20. Niehaus, W.G., Samuelsson, B. Formation of malondialdehyde from phospholipid arachidonate during microsomal lipid peroxidation. (1968) Eur J Biochem 6(1): 126-130.

21. Beauchamp, C., Fridovich, I. Superoxide dismutase: Improved assays and an assay applicable to acrylamide gels. (1971) Anal Biochem 44(1): 276-287.

22. Sinha, K.A. Colourimetric assay of catalase. (1972) Anal Biochem 47(2): 389-394.

23. Fiala, S., Fiala, A.E., Dixon, B. Gamma glutamyl transpeptidase in chemically induced rat hepatomas and spontaneous mouse hepatomas. (1972) J Nall Cancer Inst 48(5): 1393-1409.

24. Arora, C.K., Prakash, M. Biochemical techniques. (1998) Anmol publications. India 227.

25. Chomczynski, P., Sacchi, N. Single-step method of RNA isolation by acid guanidinium thiocyanate-phenol-chloroform extraction. (1987) Anal Biochem 162(1): 156-169.

26. An, W.S., Kim, H.J., Cho, K.H., et al. Omega-3 fatty acid supplementation attenuates oxidative stress, inflammation, tubolointerstitial fibrosis in the remnant kidney. (2009) Am J Physiol Renal Physiol 297(4): F895-F903.

27. Garman, J.H., Mulroney, S., Manigrasso, M., et al. Omega-3 fatty acid rich diet prevents diabetic renal disease. (2009) Am J Physiol Renal Physiol 296(2): F306-F316.

28. Livshits, A., Pflueger, A. Antioxidant Therapy for Diabetic Kidney Disease, Diseases of Renal Parenchyma. (2012) Prof. Manisha Sahay (Ed.) InTech.

29. Jayaraj, F.C., S.S., Sankal, R.D., Kaliwal, B.B. Effect of ethanolic leaf extract of Nymphaea odorata on biochemical and oxidative stress parameters of liver and pancreas in alloxan induced diabetic mice. (2012) Res Opin Anim Vet Sci 2(3): 151-157.

30. Wang, Z., Jiang, T., Li, J., et al. Regulation of renal lipid metabolism, lipid accumulation, and glomerulosclerosis in FVBdb/db MiceWith Type 2 Diabetes. (2005) Diabetes 54(8): 2338-2335.

31. Johnson, R.J., Nakagawa, T., Sanchez-Lozada, L.G., et al. Sugar, uric acid and the etiology of diabetes and obesity. (2013) Diabetes 62(10): 3307-3315.

32. Gross, J.L., de Azevedo, M.J., Silveiro, S.P., et al. Diabetic nephropathy: diagnosis, prevention, and treatment. (2005) Diabetes Care 28(1): 164-176.

33. Bauche, F., Fouchard, M.H., Jegou, B. Antioxidnat system in rat testicular cells. (1994) FEBS letters 349(3): 392-396.

34. Qujeq, D., Rezvani, T. Catalase (antioxidant enzyme) activity in streptozotocin-induced diabetic rats. (2007) International Journal of Diabetes \& Metabolism 15(1): 22-24.

35. Udaykumar, R., Kasthurirengan, S., Mariashibu, T.S., et al. Hypoglycaemic and hypolipidaemic effects of Withania somnifera root and leaf extracts on alloxan-induced diabetic rats. (2009) Int J Mol Sci 10(5): 2367-2382.

36. El-Demerdash, F.M., Yousef, M.I., El-Naga, N.I. Biochemical study on the hypoglycaemic effects of onion and garlic in alloxan-induced diabetic rats. (2005) Food and Chemical toxicology 43(1): 57-63.

37. Soltan, M.A. The effects of varieties sources of mmega-3 fatty acids on diabetes in rats. (2012) Food Nutri Sci 3(10): 1404-1412. 
38. Bottinger, E. P., Bitzer, M. TGF-beta signalling in renal disease. (2002) J Am Soc Nephrol 13(10): 2600-2610.

39. Kamat, S.G., Roy, R. Evaluation of fish oils in amelioration of diabetes-induced tissue damages in mice (Mus musculus). (2015) South Asia J Expt Biol 5(1): 32-40

40. Mieczkowska, A., Nguyen, V.C., Smulikowska, S. Effect of dietary fat on fatty acid composition of lipids from breast muscle and abdominal fat of broiler chickens. (2001) J Anim Feed Sci 10(2): 279-284.

41. Holm, T., Andreassen, A.K.., Aukrust, P., et al. Omega-3 fatty acids improve blood pressure control and preserve renal function in hypertensive heart transplant recipients. (2001) Eur Heart J 22(5): 428-436.

42. Urakaze, M., Hamazaki, T., Kashiwabara, H., et al. Favorable effects of fish oil concentrate on risk factors for thrombosis in renal allograft recipients. (1989) Nephron 53(2): 102-109.

43. Medeiros, F.J., Mothe, C.G., Aguila, M.B., et al. Long-term intake of edible oils benefits blood pressure and myocardial structure in spontaneously hypertensive rat (SHR) and streptozotocin diabetic SHR. (2005) Prostaglandins Other Lipid Mediat 78(1-4): 231-248.

44. Ikemoto, S., Takahashi, M., Tsunoda, N., et al. High fat diet induced hyperglycemia and obesity in mice: different effects of dietary oils. (1996) Metabolism 45(12): 1539-1546.

45. Schmocker, C., Weylandt, K.H., Kahlke, L., et al. Omega-3 fatty acids alleviate chemically induced Acute Hepatitis by suppression of cytokines. (2007) Hepatology 45(4): 864-869.

Ommega Online Publishers

Journal Title: Journal of Diabetes and Obesity (JDO)

Journal Short Name: J diabetes Obes
Journal ISSN: 2356-0494

E-mail: diabetes@ommegaonline.com

Website: www.ommegaonline.org 